\title{
Improved Fractional Order VSS Inc-Cond MPPT Algorithm for Photovoltaic Scheme
}

\author{
R. Arulmurugan ${ }^{1,2}$ and N. Suthanthiravanitha ${ }^{2}$ \\ ${ }^{1}$ Department of Electrical and Electronics Engineering, Anna University Regional Zone, Coimbatore, India \\ ${ }^{2}$ Department of Electrical and Electronics Engineering, Knowledge Institute of Technology, KIOT Campus, \\ NH-47 Salem to Coimbatore Road, Kakapalayam, Salem 637 504, India
}

Correspondence should be addressed to R. Arulmurugan; arul.lect@yahoo.com

Received 5 November 2013; Revised 7 January 2014; Accepted 7 January 2014; Published 2 March 2014

Academic Editor: Ismail H. Altas

Copyright (C) 2014 R. Arulmurugan and N. Suthanthiravanitha. This is an open access article distributed under the Creative Commons Attribution License, which permits unrestricted use, distribution, and reproduction in any medium, provided the original work is properly cited.

\begin{abstract}
Nowadays a hot topic among the research community is the harnessing energy from the free sunlight which is abundant and pollution-free. The availability of cheap solar photovoltaic (PV) modules has to harvest solar energy with better efficiency. The nature of solar modules is nonlinear and therefore the proper impedance matching is essential. The proper impedance matching ensures the extraction of the maximum power from solar PV module. Maximum power point tracking (MPPT) algorithm is acting as a significant part in solar power generating system because it varies in the output power from a PV generating set for various climatic conditions. This paper suggested a new improved work for MPPT of PV energy system by using the optimized novel improved fractional order variable step size (FOVSS) incremental conductance (Inc-Cond) algorithm. The new proposed controller combines the merits of both improved fractional order (FO) and variable step size (VSS) Inc-Cond which is well suitable for design control and execution. The suggested controller results in attaining the desired transient reaction under changing operating points. MATLAB simulation effort shows MPPT controller and a DC to DC Luo converter feeding a battery load is achieved. The laboratory experimental results demonstrate that the new proposed MPPT controller in the photovoltaic generating system is valid.
\end{abstract}

\section{Introduction}

Renewable energy sources are considered as an important source of energy in the 21st century that is in use to fulfill our needs and growing demands of electricity. Among all renewable energy sources, solar energy is readily available free of cost. The production cost of solar photovoltaic based system is decreased considerably. The advancement in PV technology also causes less cost per unit and thus PV technology do not contribute to global warming [1]. The extraordinary diffusion of solar PV system in electricity generation is evident from the fact that the PV scheme is anticipated to be the largest source of electricity generation among all the accessible nonconventional energy sources. They are considered feasible in residential applications and are suitable for roof top installations [2]. The PV modules are primarily a current source device and the current is produced when light falls on the surface of solar device. The characteristics curve of the PV module shows its nonlinear behavior.
The nonlinear $V$-I curve of PV module has only one point of maximum power extraction. Therefore, the energy harvesting at maximum efficiency is not simple enough. The survival of only one unique point of maximum power requires special techniques to function the scheme at the point of maximum power. These operating techniques are named as MPPT [3]. MPPT techniques control the power electronic interface such that the source impedance is matched with the load impedance and hence maximum power is transferred. In contrast with the nonlinear characteristics, MPPT techniques are vital for any solar PV system.

Different methods have been reported in literature for tracking the maximum power point (MPP). Among the 20 distinct methods reported by [4] the methods such as perturb and observe $(\mathrm{P} \& \mathrm{O})$, incremental conductance (IncCond), fractional open circuit voltage (FOCV), fractional short circuit current (FSCC), fuzzy logic, and neural network algorithm are widely used by the researchers. Among these 
methods the FOCV and FSCC are considered as offline MPPT techniques, because they isolate the PV array when they track the MPP and calculate the operating point for MPPT $[5,6]$. These techniques adopt both analog as well as digital implementations [7]. However, the periodic isolation of the PV array is power loss and the change in operating point depends on irradiance $(G)$; therefore, the periodic power loss is to be avoided; we need irradiance sensor that can measure the $G$ and hence PV array needs not to be isolated [8]. The fuzzy logic and/or neural network based MPPT technique have good performance under fast changing environmental circumstances and display improved performance than the $\mathrm{P} \& \mathrm{O}$ method [9]. However, the main drawback of this technique is that its efficiency is extremely reliant on the technical information of the engineer in calculating the error and approaching up with the fuzzy rule based table. It is importantly reliant on how a designer assembles the system based on his experience and skill. Perturb and observe algorithm can be failure under fast varying environmental circumstances. The Inc-Cond technique is constructed on the slope of the solar photovoltaic panel power curve. This technique has partly solved divergence of perturb and observe model [10].

In this paper we suggested a novel technique that will tune the online MPPT techniques based on changing weather conditions. The proposed algorithm modifies the existing conventional Inc-Cond controller based on improved fractional order variable step size which differs from the existing. The difference is based on the datasheet of the panel on the novel controller and is constant for any particular PV array. The proposed algorithm is implemented into MATLAB/Simulink environment and it is tested and validated.

The structure of the system is organized as follows. Section 2 discuss the modelling of PV modules, Improved FOVSS Inc-Cond controller and analysis of DC to DC Luo converter. Section 3 provides the simulation and experimental setup; hence results validate the controller performance. Finally Section 4 concludes remarks.

\section{Proposed System Description}

The schematic circuit diagram for the suggested system is shown in Figure 1. It contains PV panel, designed novel FOVSS Inc-Cond control algorithm, synchronous DC to DC Luo converter, and battery load. The power switches of the designed DC to DC Luo converter are controlled by the gate drivers programmed via a controller module. The designed converter delivers required levels of the output power to the stand alone battery load. The impedance of the battery load should be assumed as a suitable one for subsequent analysis. The DC to DC converters are responsible for MPPT and voltage regulations. Simulation and experimental models are established in MATLAB/Simulink and controller processor environment.

2.1. Modeling of PV Modules. PV systems convert sunlight into electrical energy without causing any environmental issues. Various equivalent models are available in the literature for better understanding of concept of PV array. Among

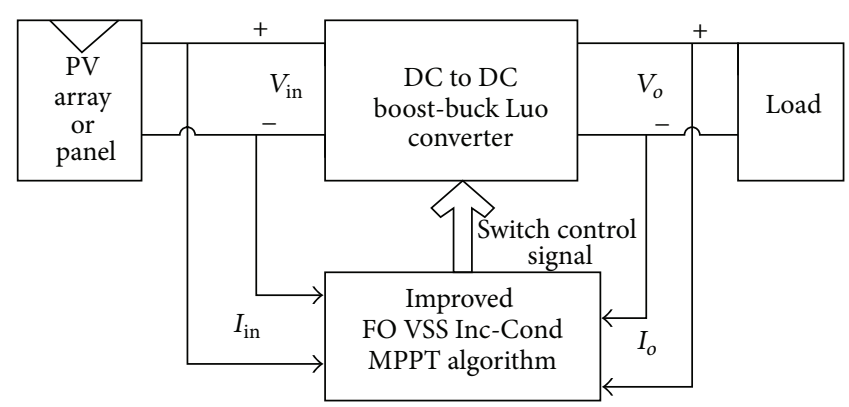

FIGURE 1: The proposed optimized novel FOVSS Inc-Cond MPPT system.

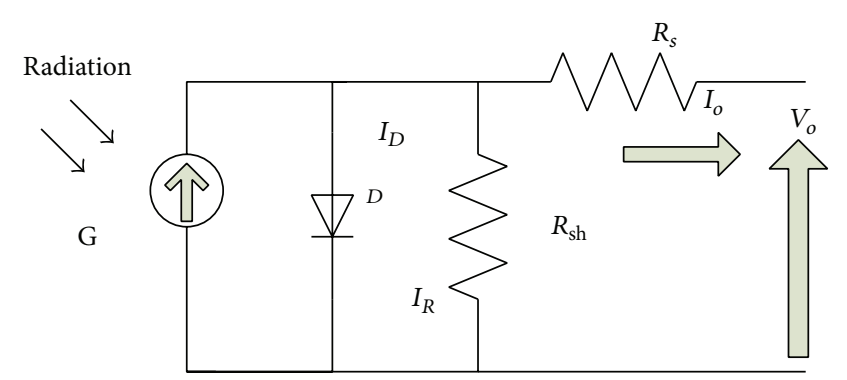

Figure 2: Equivalent circuit model of solar cell.

the models, Figure 2 is considered as good which supports accuracy and user friendliness [11]. For the constant weather conditions the curve has only one unique point of maximum power (MP) and the $V-I$ characteristic of an irradiated cell is nonlinear. It depends on several factors including the temperature and irradiance. With a varying irradiance the short circuit current varies; however, the open circuit voltage changes significantly with changes in temperature. The varying atmospheric conditions make the MPP keep shifting around the PV curve. In the PV simulation, results show the cumulative effect of the nonhomogenous weather conditions on MPP. The analytical expression based on the temperature $(T)$ and irradiance $(G)$ variation can be written as follows:

$$
I_{\mathrm{PV}}=k \cdot G \cdot S \text {, }
$$

where $I_{\mathrm{PV}}$ is the photovoltaic current source. by

$I_{d}$ is the single exponential junction current and is given

$$
I_{d}=I_{o} \cdot\left(e^{A V_{d}}-1\right) ;
$$

$I$ is the output current and is given by $I=I_{\mathrm{PV}}-I_{d}-V_{d} / R_{\mathrm{sh}}$.

$V$ is the output voltage and is given by $V=V_{d}-R_{s} \cdot I$ :

$$
\begin{gathered}
I_{\mathrm{sc}}(G, T)=I_{\mathrm{sc}}(\mathrm{STC}) \cdot \frac{G}{1000} \cdot\left(1+\alpha I_{\mathrm{sc}} \Delta T\right), \\
V_{\mathrm{oc}}(\mathrm{G}, \mathrm{T})=V_{\mathrm{oc}}(\mathrm{STC}) \cdot\left(1+\beta V_{\mathrm{oc}} \Delta T\right), \\
P_{m}(G, T)=P_{m}(\mathrm{STC}) \cdot \frac{G}{1000} \cdot(1+\gamma \rho \Delta T), \\
\eta=\frac{P_{m}}{G A}=\left(P_{m}(\mathrm{STC}) \cdot \frac{(1+\gamma \rho \Delta T)}{A}\right),
\end{gathered}
$$

where $\Delta T=T c-25^{\circ} \mathrm{C}$. 


\subsection{A New Design of Improved Fractional Order VSS Inc-Cond Controller}

2.2.1. Fractional Order Differentiator. A FO system comprised by a fractional differential or an integral equation, and systems covering few equations, has been deliberate in engineering and physical appliances, for example, active control, signal processing, and linear and nonlinear response controller. The generally utilized approaches have been anticipated for numerical assessment of fraction derivatives by RiemannLioville and Grunwald-Letnikov definition [12]. It reflects a continuous function $f(t)$, where its $\alpha$ th order derivative can be conveyed as follows [13]:

$$
\begin{gathered}
\frac{d^{\alpha} f(t)}{d t^{\alpha}}=\lim _{h \rightarrow 0} \frac{1}{h^{\alpha}} \sum_{r=0}^{\alpha}(-1)^{r}\left(\frac{\alpha}{r}\right) f(t-r h), \\
\beta=\left(\frac{\alpha}{r}\right)=\frac{\alpha !}{r !(\alpha-r) !},
\end{gathered}
$$

where $\beta$ is the coefficient binomial and $\alpha$ is an integer positive order. We use the guesstimate approach, arising the Grunwald Letnikov definition as

$$
D_{t}^{\alpha} f(t) \approx h^{-\alpha} \sum_{r=0}^{[t / h]}(-1)^{r} \beta f(t-r h)
$$

For generalization, it is suitable to adopt $t=n h$, where " $t$ " is the opinion at which the derivative is appraised and $h$ is the discretization step. We can rewrite the estimate of the $\alpha$ th derivative as follows:

$$
\begin{gathered}
D_{t}^{\alpha} f(t)=\frac{d^{\gamma}}{d t^{\gamma}}\left[D_{t}^{-(\gamma-\alpha)}\right], \\
D_{t}^{\alpha} f(t) \approx\left(\frac{t}{n}\right)^{-\alpha} \sum_{r=0}^{n-1} \frac{\Gamma(r-\alpha)}{\Gamma(-\alpha) \Gamma(r+1)} f\left(t-r \frac{t}{n}\right),
\end{gathered}
$$

where $\gamma$ is an integer satisfying $\gamma-1<\alpha \leq \gamma$. Clearly the FO calculus leads to an immeasurable dimension, while the integral calculus is a finite dimension. Reflect $f_{m}(t)=t^{m}, m=$ $1,2,3,4 \ldots$, and the $\alpha$ th derivative is

$$
D_{t}^{\alpha} t^{m} \approx \frac{t^{m-\alpha}}{\Gamma(-\alpha)} n^{\alpha} \sum_{r=0}^{n-1} \frac{\Gamma(r-\alpha)}{\Gamma(r+1)}\left(1-\frac{r}{n}\right)^{m} .
$$

If we expand $[1-(r / n)]^{m}$ by the binominal theorem $[3,6]$, (10) becomes

$$
\begin{gathered}
D_{t}^{\alpha} t^{m} \approx \frac{t^{m-\alpha}}{\Gamma(-\alpha)} \sum_{k=0}^{m}(-1)^{k}\left(\frac{m}{k}\right) n^{\alpha-k} \sum_{r=0}^{n-1} \frac{\Gamma(r-\alpha)}{\Gamma(r+1)} r^{k}, \\
K \equiv \sum_{r=0}^{n-1} \frac{\Gamma(r-\alpha)}{\Gamma(r+1)} r^{k} .
\end{gathered}
$$

If $y$ is an unstipulated and if $j$ is an integer positive, then $y, j$ fractional is defined as

$$
\begin{gathered}
y^{(j)}=y(y-1)(y-2) \cdots(y-j-1), \\
\Gamma(y+1)=y^{(j)} \Gamma(y-j+1) .
\end{gathered}
$$

So, an integral power of $y$ can be expressed as a factorial polynomial, as

$$
y^{k}=\sum_{j=1}^{k} \xi_{j}^{k} y^{(j)}=\sum_{j=1}^{k} \xi_{j}^{k} \frac{\Gamma(y-j+1)}{\Gamma(y+1)},
$$

where the $\xi$ is the sterling values. Let $y=r$ in (14) be substituted in (12) and replace $n$ by $n-j$ and $\alpha$ by $\alpha-j$; then

$$
K=\sum_{j=1}^{k} \xi_{j}^{k}\left(\sum_{r=0}^{n-1} \frac{\Gamma(r-\alpha)}{\Gamma(r+1-j)}\right)=\sum_{j=1}^{k} \xi_{j}^{k} \frac{\Gamma(n-\alpha)}{\Gamma(n-j)}\left(\frac{1}{j-\alpha}\right) .
$$

Equation (11) becomes

$$
\begin{aligned}
D_{t}^{\alpha} t^{m} \approx & \frac{t^{m-\alpha}}{\Gamma(-\alpha)} \sum_{k=0}^{m}(-1)^{k}\left(\frac{m}{k}\right) \sum_{j=0}^{k} \frac{\xi_{j}^{k} n^{\alpha-k} \Gamma(n-\alpha)}{(j-\alpha) \Gamma(n-j)}, \\
& \lim _{n \rightarrow \infty} n^{\alpha-k} \frac{\Gamma(n-\alpha)}{\Gamma(n-j)}= \begin{cases}1, & \text { if } j=k, \\
0, & \text { if } j<k,\end{cases}
\end{aligned}
$$

where

$$
\sum_{k=0}^{m}(-1)^{k}\left(\frac{m}{k}\right) \frac{1}{(k-\alpha)}=B(-\alpha, m+1) .
$$

A general fractional order differentiator can be expressed as follows:

$$
D_{t}^{\alpha} t^{m} \approx \frac{\Gamma(m+1)}{\Gamma(m+1-\alpha)} t^{m-\alpha} .
$$

For all $\alpha$, positive, negative, and/or zero, $m=0,1,2,3,4 \ldots$. Note, the select of $\alpha$ can be seen as selecting the spectacles that will be modeled. By selecting $0<\alpha<1$, anomalous phenomena, such as heat conduction, diffusion, viscoelasticity, and electrode-electrolyte polarization, can be described [1].

2.2.2. Design of New Improved VSS Inc-Cond Controller. Generally step size is fixed for the Inc-Cond MPPT technique. The produced power from the PV panel with a higher step size plays to quicker dynamics but results in extreme steady state fluctuations and subsequent poor efficiency [14]. This condition is inverted through the MPPT by operating with a lesser step size. Thus, the tracking with constant step size makes a suitable trade-off among the fluctuation and dynamics. Thus the problem can be resolved with VSS restatement $[15,16]$. Even though all the conventional methods are simple perturb and observe method produce oscillations occurring at maximum power point and hence output power is not achieved at desired level and results in poor efficiency. The Inc-Cond method is envisioned to resolve the difficulty of the conventional perturb and observe method under quick varying environment circumstances [17]. Hence, in this paper the performance of the FOVSS Inc-Cond method in quickly varying environment conditions by using voltage versus current graph [18]. Condition 1: the curve power versus voltage is positive and the indication of the altering voltage and current 


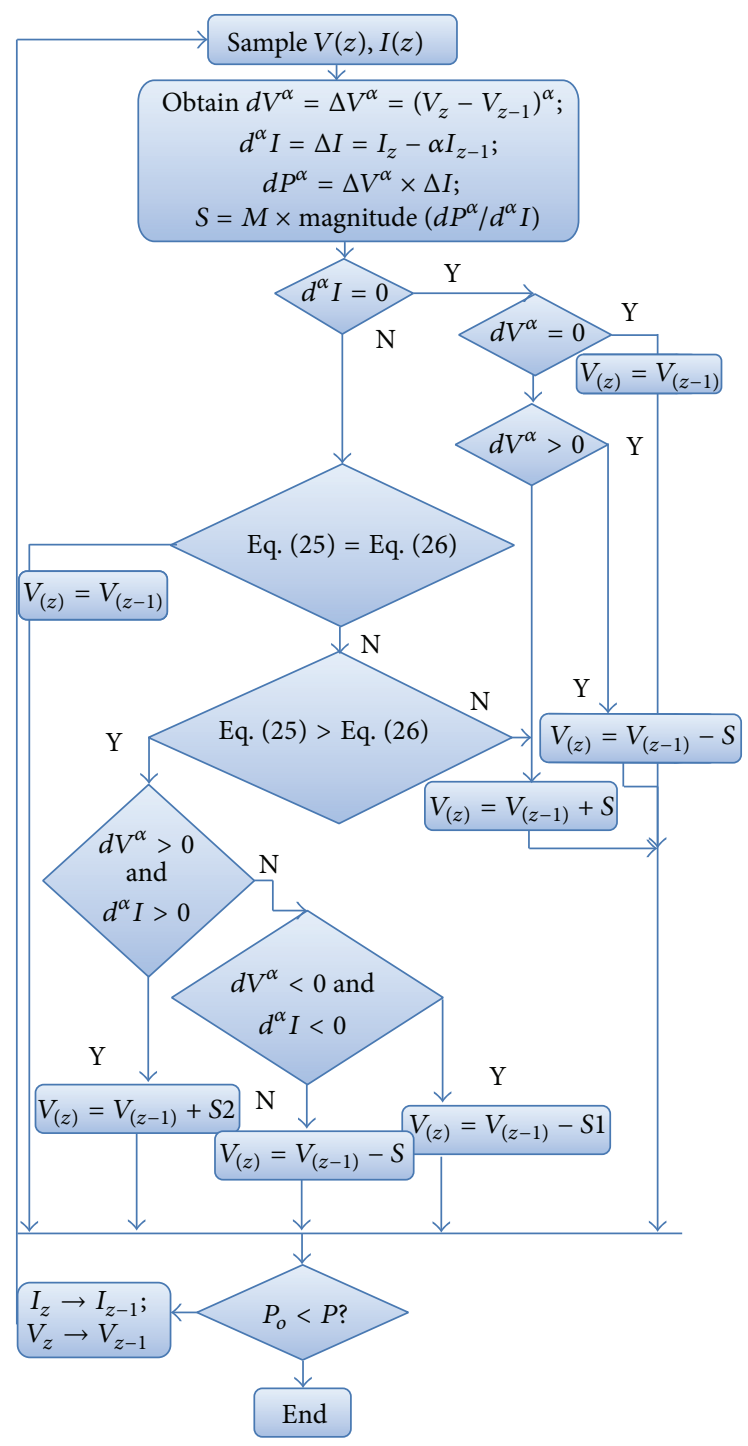

FIgURE 3: Novel improved FOVSS Inc-Cond MPPT algorithm.

is the same, simultaneously; the algorithm recognizes that $G$ is in quickly accumulative environmental circumstances and reduces the voltage. Condition 2: on the other side, if the slope of the power versus voltage graph is positive, altering current and voltage are opposite; concurrently, the algorithm recognizes that it is quickly reducing environment situations and rises the voltage. Condition 3: lately, if altering $I$ and $V$ are in conflicting directions, the algorithm for tracing supreme power upsurges the $V$, as the Inc-Cond conventional algorithm. Thus this algorithm eludes difference from the real MPP in quickly varying environmental circumstances.

In this report, a VSS procedure is suggested for the improved Inc-Cond tracking technique and is dedicated to search an easier and active way to increase tracking dynamic as well as correctness. In every tracking application, the possible power follower is attained by joining a DC to DC converter among the PV panel and load system [19]. The power output of the PV is utilized for energetic control of the DC to DC converter pulse width modulation $(D)$ to diminish well the complication of the structure [20]. The flowchart of the FOVSS improved Inc-Cond tracking algorithm is illustrated in Figure 3, where the power DC to DC converter PWM $(D)$ recapitulation step size tuned automatically. The power output of PV panel is involved to regulate the power DC to DC converter PWM (D), donating to a shortened control scheme, where the outputs $I$ and $V$ of the PV array represent $V_{(z)}$ and $I_{(z)}$ at time $z$, respectively. The VSS implemented to diminish the problem represented above is written in the equation as follows:

$$
D(z)=D(z-1) \pm M \times\left|\frac{d P}{d V}\right| .
$$

In the above equation $M$ denotes the scaling factor, which is adjusted at the period to regulate the step size. The VSS can also be recognized from the incline of the power versus duty cycle graph in [16] for perturb and observe tracking written as follows:

$$
D(z)=D(z-1) \pm M \times\left|\frac{\Delta P}{\Delta V}\right| .
$$

In the above written equation $\Delta D$ represents the change in stage $D$ at earlier sample period. As illustrated in the power versus voltage, the derivative of $(d P / d V)$ of a PV panel can be seen to be changing efficiently and is suggested in [15] as an appropriate constraint for determining the VSS of the perturb and observe method. So, the derivative $(d P / d V)$ is also working herein to control the VSS for the Inc-Cond tracking method. The modern rule for PWM (D) can be acquired as the following equation:

$$
D(z)=D(z-1) \pm M \times\left|\frac{P(z)-P(z-1)}{V(z)-V(z-1)}\right| .
$$

The $M$ is necessarily determined by the effectiveness of the tracking structure. Physical fine-tuning of this constraint is boring and resultant output may be effective only for a given structure and operating circumstance [15]. A modest technique is used to determine whether the $M$ is suggested here. Initially higher step size of the maximum duty cycle $\left(D_{\max }\right)$ for constant step size tracking scheme was selected. By such results, the active development is best adequate but gives poor steady state performance. The stable state assessment instead of dynamic assessment in the start-up development of the magnitude $P$ divided by $V$ of the PV panel output can be estimated under the constant VSS working with maximum duty cycle, which will be selected as the superior controller as VSS Inc-Cond tracking technique. To confirm the conjunction of the tracking superior rule, the variable step (VS) rule should observe the following:

$$
M \times\left|\frac{d P}{d V}\right|_{\text {fized step }=\Delta D_{\max }}<\Delta D_{\max } .
$$

In the above equation $|d P / d V|_{\text {fized step }=\Delta D_{\max }}$ is the $|d P / d V|$ at FSS operation of maximum duty cycle. The $M$ can be obtained as follows:

$$
M<\frac{\Delta D_{\max }}{|d P / d V|_{\text {fized step }=\Delta D_{\max }}} .
$$


In the equation above, the VSS improved Inc-Cond tracking will be operating with FSS of the early set superior controller $\Delta D_{\max }$. The above equation delivers an easier supervision to determine the $M$ of the VSS Inc-Cond tracking technique. With the fulfillment of above calculation, superior scaling factor shows a relatively quick reaction than a minor scaling factor. The SW will become minute as derivative power to voltage becomes very slight nearby the maximum power [21].

\subsubsection{The Control Process of Improved FOVSS Inc-Cond} Algorithm. The $V-I$ characteristics of a single module are resolute and enlarge to control the performance of a PV array, as illustrated in Figure 3. It seems $d I / d V<0$, with rising $V$ as $I$, is diminishing. Based on (1)-(3), current and voltage are contingent on environment and electricity transmission. The irregular singularities can be designated as FOD. Thus, the $d I / d V$ can be altered as follows:

$$
\begin{gathered}
\frac{d^{\alpha} V(I)}{d^{\alpha} I}=\lim _{\Delta V \rightarrow 0} \frac{V^{\alpha}(I)-V_{o}^{\alpha}(I-\Delta I)}{\Delta I}, \\
\frac{d V^{\alpha}}{d^{\alpha} I} \approx \frac{\left(V-V_{o}\right)^{\alpha}}{I-\alpha I_{o}} .
\end{gathered}
$$

The efficiency of the weighing $\Delta I$ is altered as $\alpha>0$, and $\alpha$ is an even number. If $\alpha=1$, then it yields to the rate of change quickness. For $\alpha=2$ outside the range, it yields acceleration. Therefore, for $0<\alpha<1$ the appearance can be called as the fractional rate of the alteration of operation. Equation (25) is utilized to direct the FO incremental variations of the $I$ and $V$ of the PV array. The VSS incremental conductance load can be modified as follows:

$$
\begin{aligned}
& \frac{d^{\alpha}}{d V^{\alpha}}\left(-\frac{V_{o}}{I_{o}}\right) \\
& \quad=\left(-\frac{1}{I_{o}}\right) \frac{d^{\alpha} V_{o}^{\alpha}}{d^{\alpha} I}+\left(-V_{o}\right) \frac{d^{\alpha} I_{O}^{-1}}{d^{\alpha} I} \\
& \quad=\left(-\frac{1}{I_{o}}\right)\left(\frac{\Gamma(2)}{\Gamma(2-\alpha)}\right) V_{o}^{1-\alpha}+\left(-V_{o}\right) \frac{\Gamma(0)}{\Gamma(-\alpha)} I_{O}^{1-\alpha},
\end{aligned}
$$

where $\operatorname{Res}(\Gamma,-z)=\left((-1)^{z} / z !\right) Z=0,-1,-2,-3,-4, \ldots$ with remainder $\Gamma(0)=\operatorname{Res}(\Gamma-0)=1$. Thus the procedure of improved FOVSS Inc-Cond method examines the $V$ as a variable at which the MPP has an increasing or diminishing duty cycle.

Figure 3 shows the flowchart of the improved FOVSS Inc-Cond control algorithm. By using the radiation meter, this control technique can modify the working mode in the program. Based on the power output of the PV module MPP varies, hence the suggested control technique increases or diminishes the voltage output of the PV module as a similar path and it can be traced to the MPP. It regulates the $D$ by the immediate values $I_{z}$ and $V_{z}$ at existent iteration step and their consistent values of $I_{z-1}$ and $V_{z-1}$ deposited at the end of the foregoing repetition step. The VSS incremental changes in $I$ and $V$ are approached as $d^{\alpha} I \approx\left(I_{z}-\alpha I_{z-1}\right)=$ $\Delta I$ and $d V^{\alpha} \approx\left(V_{z}-V_{z-1}\right)^{\alpha}=\Delta V^{\alpha}$, correspondingly. To evade underestimating the employed state under numerous

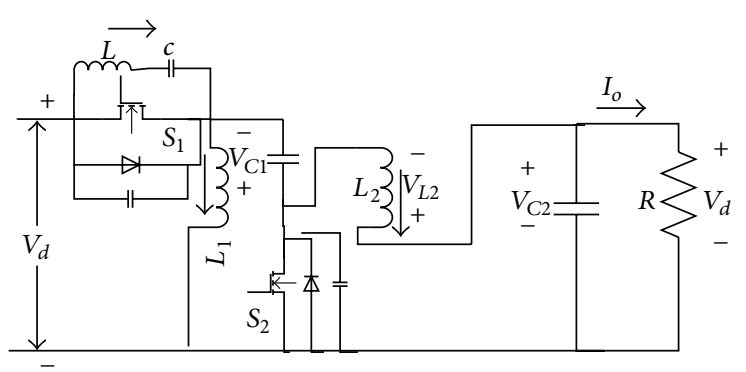

Figure 4: DC to DC Luo converter.

conditions, the first voltage $V_{z}$ can be set to $0 \mathrm{~V}$ or default values rendering to the $T$ differences. Rendering to the four conclusions, the control process of improved FOVSS IncCond method algorithm can be expressed as follows.

Situation one: if $\left(\Delta V^{\alpha}=0\right.$ and $\left.\Delta I=0\right)$ not any controller accomplishment is required.

Situation two: if $\left(\Delta I=0\right.$ and $\left.\Delta V^{\alpha}>0\right)$ a controller action is required to enhance the $\Delta V^{\alpha}$ to present voltage $V$ with a cumulative $D$ step size.

Situation three: if $\left(\Delta I=0\right.$ and $\left.\Delta V^{\alpha}<0\right)$ a controller action is required to decrease the $\Delta V^{\alpha}$ to present voltage $V$ with a diminishing $D$ step size.

Situation four: calculated power output is equal to multiplication of voltage and current output, $P=V I$. If $P_{o}<P$, modernize the $V: V_{z-1}=V_{z}$ and $I_{z-1}=I_{z}$ and then dismiss the controller process.

2.3. Analysis of Synchronous DC to DC Luo Converter. When recommending a MPP tracker, the most important process is to choose and analyze a highly suitable converter, which is invented to function as the foremost fragment of the tracker (MPPT). Therefore switching mode power supplies are suitable to operate with high efficiency. Among all the complete topologies existing, the series of buck-boost converters provide the opportunity to have either higher or lower output voltage compared with the input voltage. The conventional buck-boost formation is cheaper than the Luo one, even though some drawbacks occur, such as less efficient, weak transient reaction, high peak current in power apparatuses, and discontinuous current input. On the other side, the Luo converter has the highest efficiency with low switching losses amongst nonisolated DC to DC converters and no negative polarity regulated output voltage compared to the input voltage. It can deliver an improved current output characteristic due to the output stage inductor. Thus, the Luo configuration is an appropriate converter to be active in deceiving the MPPT [21].

The DC to DC Luo converter provides a positive polarity regulated output voltage with respect to the input voltage which is shown in Figure 4 . The process of the synchronous Luo converter with ZVS and ZCS technique is for dropping the switching loss of the primary switch. In addition, the freewheeling diode is replaced by power switch to reduce 


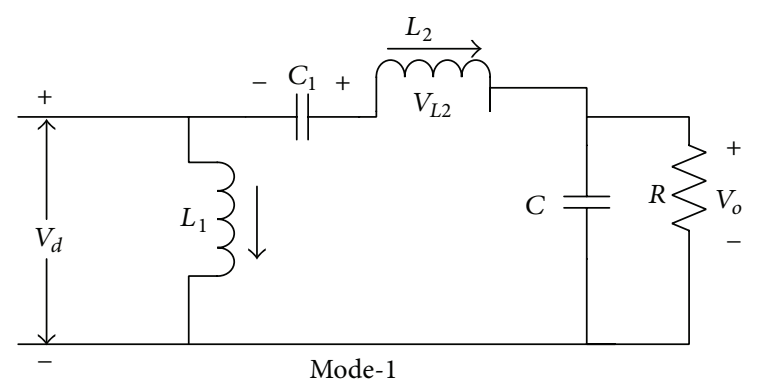

(a)

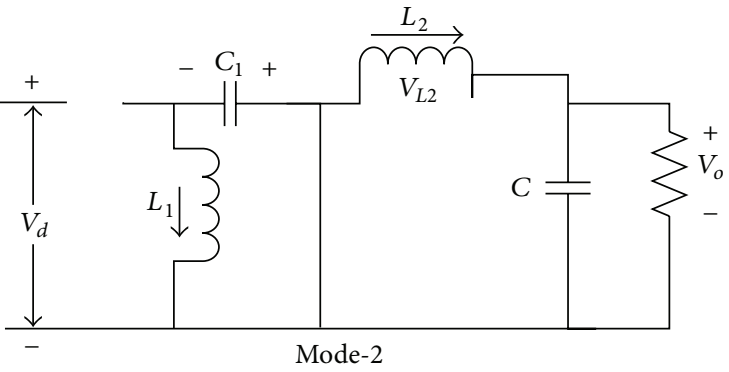

(b)

FIGURE 5: Equivalent modes of converter: (a) main switch on; (b) main switch off.

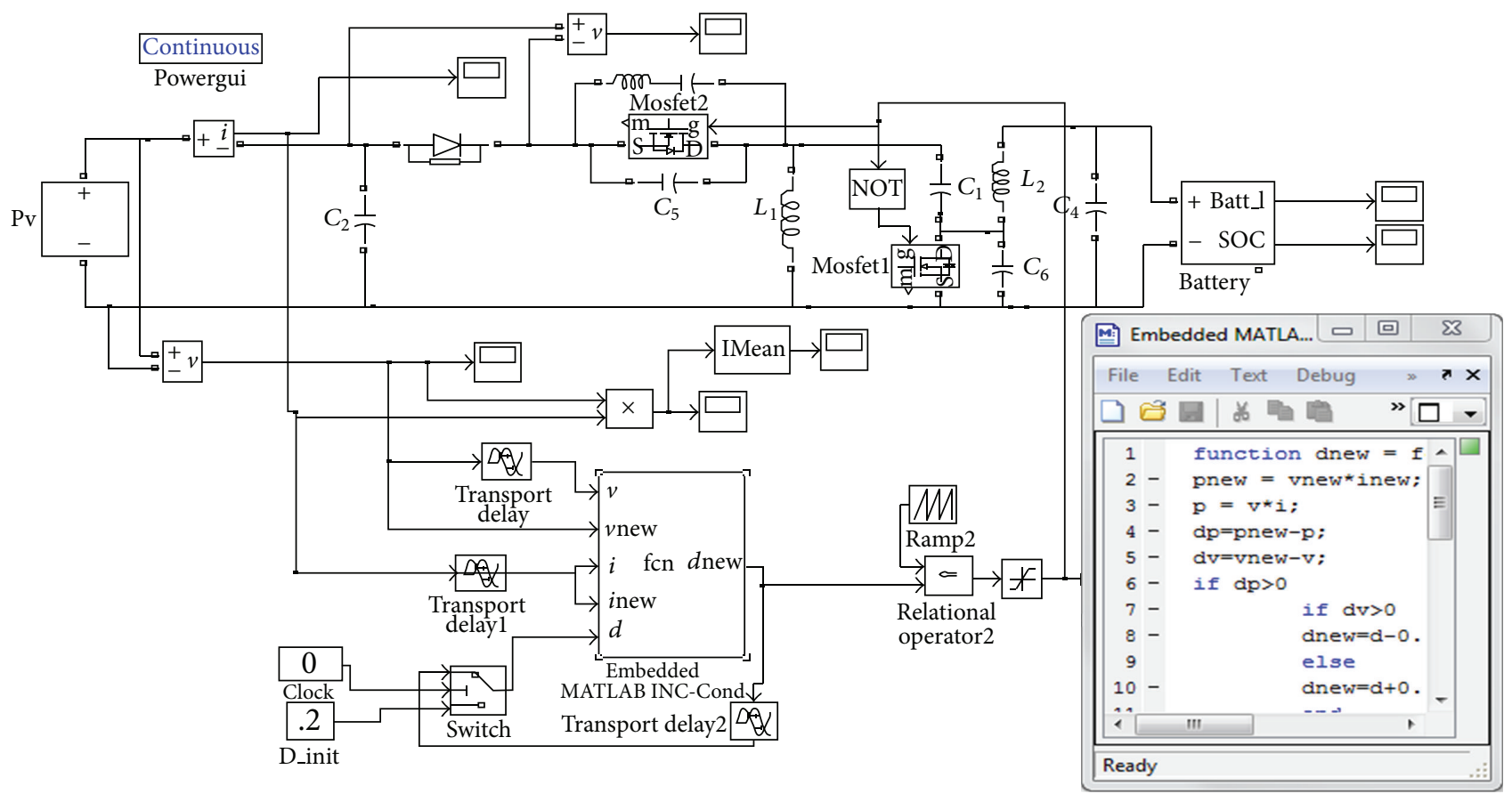

FIgURE 6: Simulation layout of the proposed FOVSS Inc-Cond system.

conduction losses too. The designed circuit, two powers MOSFET switches are utilized to reduce switching and conduction losses. The energy storage elements are capacitors $C_{1}$ and $C_{2}$ and inductors $L_{1}$ and $L_{2} . R$ is the load resistance. To analyze the process of the DC to DC Luo converter, the circuit can be divided into two equivalent modes [22].

2.3.1. Modes of Operation. In mode one operation, when the power switch $S_{1}$ is turned on, the inductor $L_{1}$ is charged by the input supply voltage $V_{\text {in }}$. At similar time, the inductor $L_{2}$ absorbs the energy from input source and the primary capacitor $C_{1}$. The load is delivered by the capacitor $C_{2}$. The equivalent method of DC to DC Luo converter operating mode 1 is shown in Figure 5(a).

In the mode 2 process, when the switch is in turned off state, the input current drawn from the source becomes zero, as shown in Figure 5(b). The inductor current $I_{L 1}$ flows through the power $S_{2}$ to charge the capacitor $C_{1}$. The inductor second current $I_{L 2}$ flows through $C_{2}$ to load resistance circuit and the second switch $S_{2}$ to keep it continuous.

\section{Simulation Results and Discussion}

3.1. Simulation Setup. The PV array is modeled and coupled with the DC to DC Luo converter and is controlled by suggested tracking algorithm. To examine the performance and effectiveness of suggested FOVSS Inc-Cond controller, it is tested on the experimental prototype of the photovoltaic MPPT controller and the complete simulation structure of a proposed system is illustrated in Figure 6 [23]. It is made up of multi and mono crystalline silicon materials of 40 watt PV array. The Table 1 shows the specifications for single 10 watt PV module [10].

3.2. Analysis of $P V$ Results. To confirm the enactment of the suggested system the $V-I$ and $V-P$ characteristics of single PV 
TABLE 1: Electrical parameters of PV module.

\begin{tabular}{lccccc}
\hline Designation & Peak maximum power & Peak maximum voltage & Peak maximum current & Open circuit voltage & Short circuit current \\
\hline Value [units] & $10 \mathrm{Wp}$ & $16.4 \mathrm{~V}$ & $0.610 \mathrm{~A}$ & $21 \mathrm{~V}$ & $0.700 \mathrm{~A}$ \\
\hline
\end{tabular}

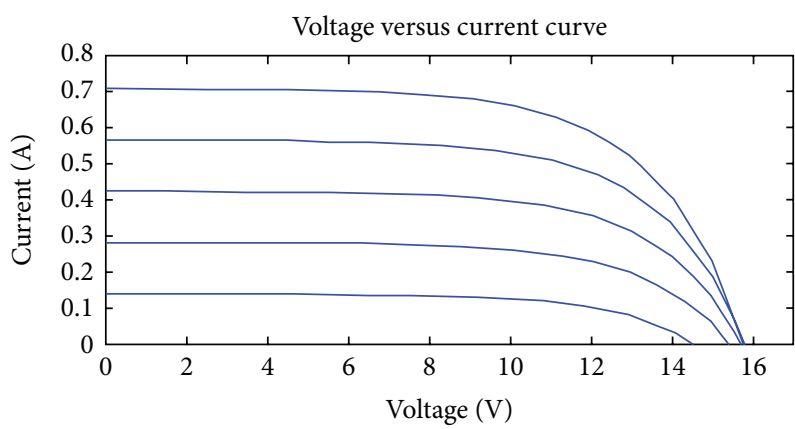

- Model@ $0.2 \mathrm{KW} / \mathrm{m}^{2} / 25^{\circ} \mathrm{C}-$ Model @ $0.8 \mathrm{KW} / \mathrm{m}^{2} / 40^{\circ} \mathrm{C}$

- Model@ $0.4 \mathrm{KW} / \mathrm{m}^{2} / 30^{\circ} \mathrm{C}$

- Model @ $0.6 \mathrm{KW} / \mathrm{m}^{2} / 35^{\circ} \mathrm{C}$

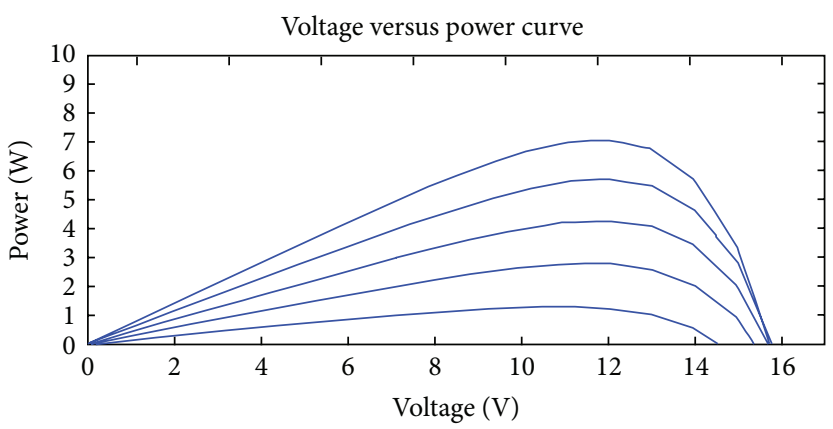

$\begin{array}{rrr}\text { Model @ } 0.2 \mathrm{KW} / \mathrm{m}^{2} / 25^{\circ} \mathrm{C} & - \text { Model @ } 0.8 \mathrm{KW} / \mathrm{m}^{2} / 40^{\circ} \mathrm{C} \\ \text { Model @ } 0.4 \mathrm{KW} / \mathrm{m}^{2} / 30^{\circ} \mathrm{C} & \text { Model } 1 \mathrm{KW} / \mathrm{m}^{2} / 45^{\circ} \mathrm{C}\end{array}$

—_ Model@ $0.6 \mathrm{KW} / \mathrm{m}^{2} / 35^{\circ} \mathrm{C}$

FIGURE 7: Simulated $V-I$ and $V$-P characteristics of single PV module with variation of solar G\&T, which are installed on the floor of the laboratory at GCE, Salem (sponsored by IIT, Bombay).

module of proposed panel are plotted for different values of solar insulation and cells temperature as shown in Figure 7. Simulation uses the standard design method which shows that an increased number of modules can deliver a nominal level of operating charging current for normal range of $G$. From this PV curves, it was discovered that the decrease in the maximum power causes increase in temperature. The following operating conditions are observed from this study: (1) when increasing the load current causes drops in the PV voltage; (2) when increase in temperature causes reduction in power output due to rises of internal resistance across the cell; (3) when increasing the insolation, the power output $\mathrm{PV}$ increases as more photons hit out electronics and further current flow causing higher recombination. The variation of power output acts as a function of module voltage and is affected by altered working conditions. Also, the output $V$ versus $I$ characteristics of the single PV module is observed under various conditions of $T$ and $G$ [23].

3.3. Results for Proposed System under Dynamic Weather Conditions. To distinguish the enactment of the designed improved FOVSS Inc-Cond MPPT control algorithm which can automatically regulate the step size with the traditional incremental conductance algorithm, the MATLAB simulations are constructed under similar circumstances. The sampling period carried out for the conventional Inc-Cond algorithm was selected as 0.02 second. Consequently, the PWM duty cycle $(D)$ of the DC to DC Luo converter is modernized for each 0.02 seconds. The performance of output power of conventional Inc-Cond maximum tracking control with a fixed size step is 0.02 under an irradiance step various from $200 \mathrm{~W} / \mathrm{m}^{2}$ at temperature $25^{\circ} \mathrm{C}$ to $800 \mathrm{~W} / \mathrm{m}^{2}$ at temperature $27^{\circ} \mathrm{C}$ at 0.5 seconds which are shown in
Figure 8(a). To differentiate, the consistent photovoltaic power output response of the designed improved FOVSS IncCond maximum tracking control algorithm with allowable possible duty size $\Delta D$ is 0.10 and is illustrated in Figure $8(\mathrm{~b})$. It is observed that the fluctuations happening at steady state in conventional Inc-Cond algorithm are nearly eliminated by the design of improved FOVSS Inc-Cond tracking algorithm. Also, the dynamic enactment of the designed method is noticeably quicker than the conventional technique by fixed size step of 0.02 . The outcomes point out that the fluctuations at steady state conditions are significantly reduced by using the designed FOVSS Inc-Cond maximum tracking control algorithm.

The performance is compared between conventional IncCond and proposed FOVSS Inc-Cond tracking algorithm and is obtained in Table 2. Compared with the conventional incremental conductance, fixed step size of $\Delta D$ is 0.10 which shows good performance but results in greater steady state fluctuation. The proposed FOVSS Inc-Cond technique solves this problem. The fluctuation at the steady state is nearly exterminated by the use of very small magnitude of $\left(d P^{\alpha} / d^{\alpha} I\right)$ and the resultant output power of PV array is $39.5 \mathrm{~W}$. Furthermore, the dynamic performance of proposed FOVSS Inc-Cond technique is quicker than conventional IncCond technique which is shown in Figure 8.

3.4. Experimental Setup and Results. The process of improved FOVSS Inc-Cond maximum tracking algorithm has been assessed by experiment. The experimental test was carried out on the laboratory test bench of the standalone PV system installed on the floor of the Electrical and Electronics Engineering at Government College of Engineering, Salem, India, sponsored by IIT, Bombay. A model of the suggested scheme 
TABLE 2: Comparison of conventional and proposed tracking algorithm performance.

\begin{tabular}{|c|c|c|c|c|c|c|}
\hline \multirow{2}{*}{ Technique } & \multirow{2}{*}{ Parameter } & \multicolumn{2}{|c|}{$\begin{array}{c}\text { Irradiance-200 W/m } \mathrm{m}^{2} \\
\text { and temperature is }-25^{\circ} \mathrm{C}\end{array}$} & \multicolumn{2}{|c|}{$\begin{array}{c}\text { Irradiance- } 800 \mathrm{~W} / \mathrm{m}^{2} \\
\text { and temperature is }-27^{\circ} \mathrm{C}\end{array}$} & \multirow{2}{*}{$\begin{array}{l}\text { Under steady state } \\
\text { conditions }\end{array}$} \\
\hline & & Output power & $\begin{array}{l}\text { Sampling period } \\
\text { in seconds }\end{array}$ & Output power & $\begin{array}{l}\text { Sampling period } \\
\text { in seconds }\end{array}$ & \\
\hline $\begin{array}{l}\text { Conventional } \\
\text { Inc-Cond }\end{array}$ & $\Delta D=0.10$ & $P_{o}: 12.9 \mathrm{~W}$ & 0.02 seconds & $P_{o}: 38.7 \mathrm{~W}$ & 0.5 seconds & $\begin{array}{l}\text { More fluctuation } \\
\text { takes place }\end{array}$ \\
\hline $\begin{array}{l}\text { Proposed FOVSS } \\
\text { Inc-Cond } \\
\text { algorithm }\end{array}$ & $M=0.056$ & $P_{o}: 13.5 \mathrm{~W}$ & 0.02 seconds & $P_{o}: 39.5 \mathrm{~W}$ & 0.5 seconds & $\begin{array}{l}\text { Eliminate the } \\
\text { fluctuation }\end{array}$ \\
\hline
\end{tabular}

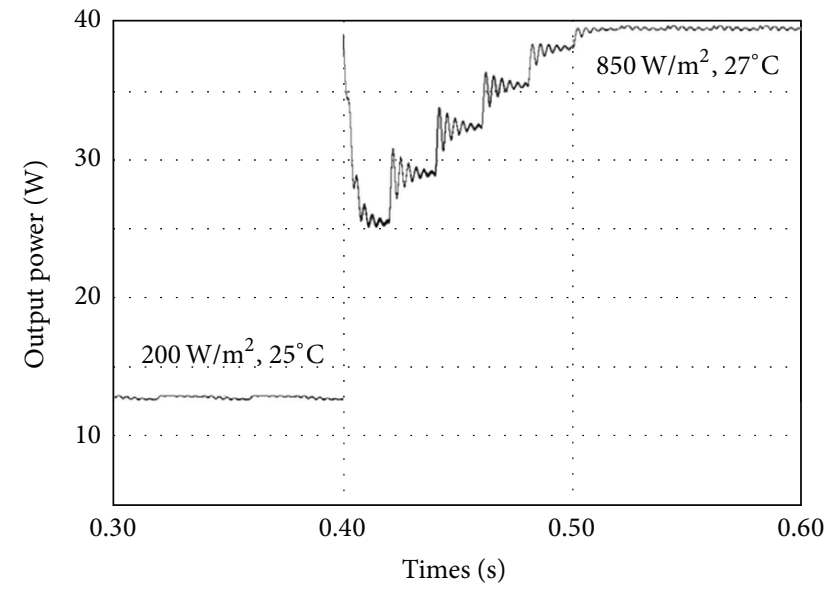

(a)

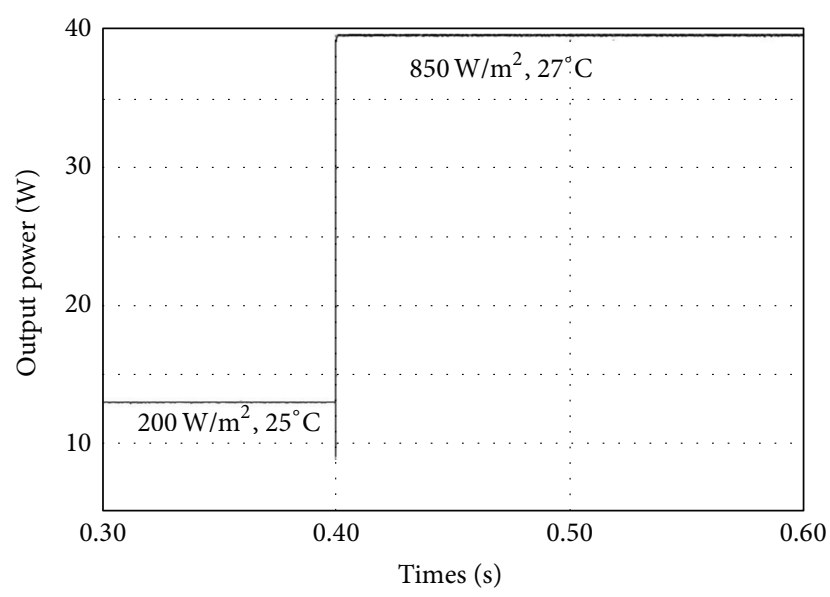

(b)

FIGURE 8: Simulated photovoltaic power output response under sudden change in G\&T: (a) conventional Inc-Cond algorithm; (b) designed improved FOVSS Inc-Cond tracking technique.

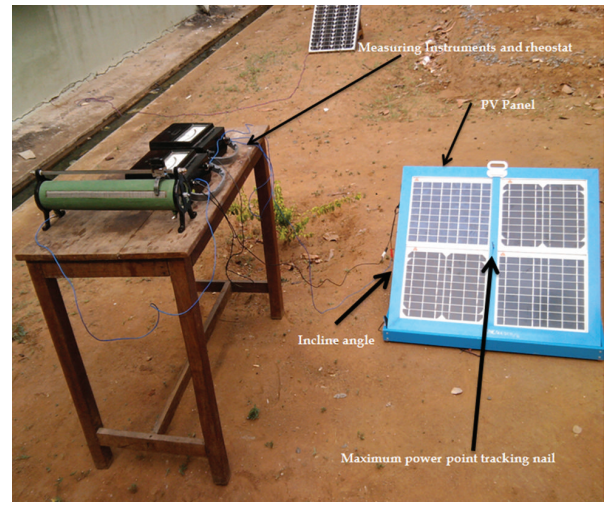

(a)

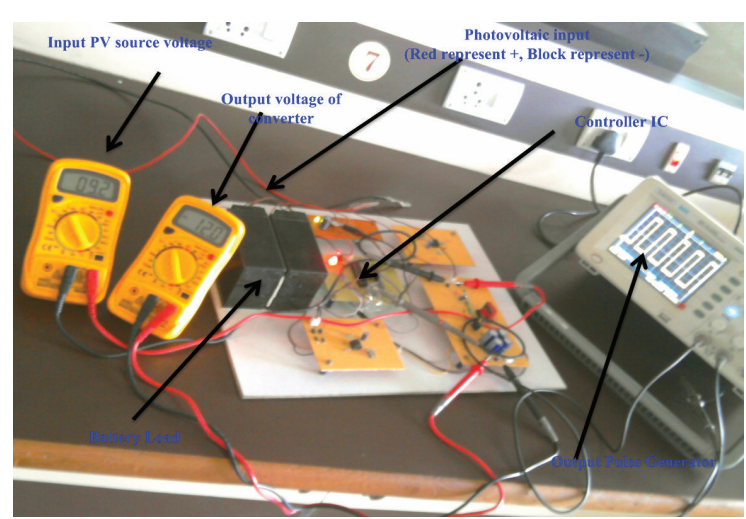

(b)

FIGURE 9: Photos of prototype setup: (a) PV array; (b) DC to DC Luo converter with improved FOVSS Inc-Cond MPPT algorithm.

depicted in Figure 9 is composed of (a) photovoltaic panel and (b) DC to DC Luo converter with suggested controlling technique. The DC to DC Luo converter specifications are selected as follows. The input voltage is $21 \mathrm{~V}$, capacitance $C_{1}$ and capacitance $C_{2}$ are $220 \mu \mathrm{F}$, inductances $L_{1}$ and $L_{2}$ are $1.5 \mathrm{mH}$ and $2 \mathrm{mH}$, respectively, switching frequency is $10 \mathrm{Khz}$, and $12 \mathrm{~V}$ battery. Note that these passive components are designated to fill design criteria distilled based on equations. In the test, there are four PV modules mounted side by side and connected in series and parallel manner. Atmega 8 microcontroller was used to deliver the control pulses for the DC to DC Luo converter. The $C$ language code of 


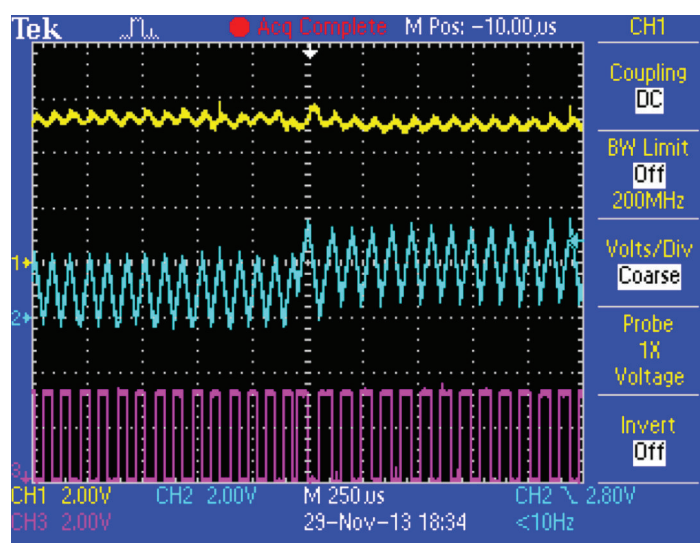

FIGURE 10: Initial waveforms of MPPT with PV array (channel-1: PV voltage, channel-2: PV current, channel-3: gate pulse).

the improved FOVSS Inc-Cond controller and PWM generator system is constructed, debugged, and executed with the assistance of the Arr studio development tool and Proisp software [16, 17].

The initial graph with improved FOVSS Inc-Cond peak tracking control algorithm is illustrated in Figure 10. When the scheme attains close to the peak power, the size of the step becomes very tiny, outcoming in an excellent power graph. The power and current of the PV rises to a length due to great step size change at the starting. An adjustable resistive load was straight joined with the PV panel as well to investigate the peak power. The peak power distinguishing between the PV panel could be fashioned and the modules outputs with the suggested FOVSS Inc-Cond peak tracking technique are within numerous watts. Thus, the peak tracking efficiency of the suggested technique under the present situation is about $98.92 \%$. The peak tracking efficiency variance is not clear due to the minor step size selected for the fixed step size Inc-Cond algorithm. The reason of this paper is to advance the dynamic reaction and investigate the change in irradiance further [1820]. A dual switch is familiarized to series with one set of series assembled PV module to simulate the consequence of the irradiance on the PV scheme. When the SW is off or on, both the voltage and power output of the PV panel will hit a step variation, simulating a poor operational condition for the maximum tracking control. When the SW is off, the modules of the PV altered from three to four. The equivalent PV scheme power output graphs with the suggested improved FOVSS Inc-Cond peak tracking algorithm controller are illustrated in Figure 11, while Figure 12 demonstrates individuals graph for the modules of the PV that suddenly varied from four to three. The sampling periods of the improved FOVSS Inc-Cond peak tracking algorithm are selected to achieve almost steady state accuracy. From the outcome of the figures, it can be illustrated that the PV scheme with improved VSS gets the peak power within 1.3 seconds to trace the peak power when the power output of the PV is instantly varied. From the result it is concluded that the improved FOVSS IncCond peak tracking control algorithm has the best dynamic enactment.

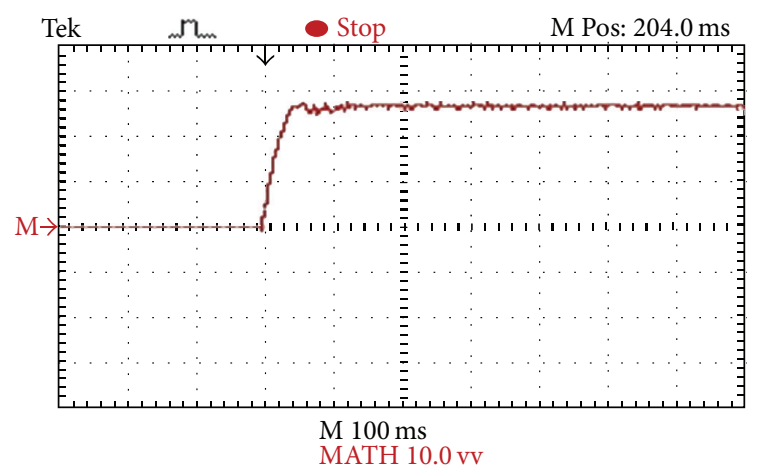

FIGURE 11: Change in power when the number of PV modules is increased from three to four.

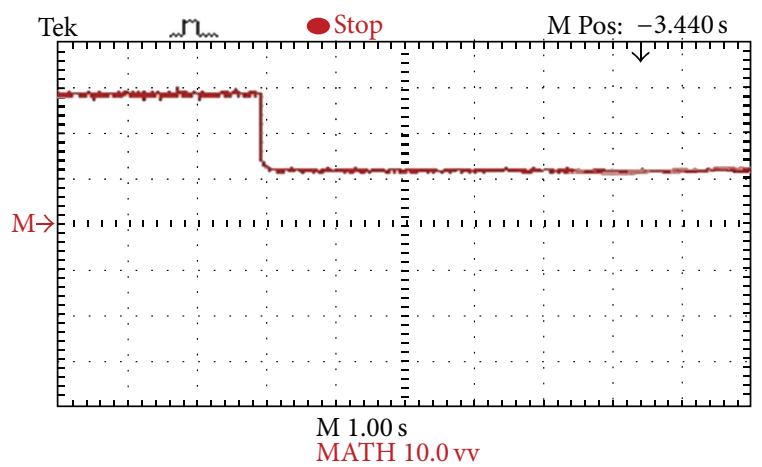

FIGURE 12: Change in power when the number of PV modules is decreased from four to three.

\section{Conclusion}

In this paper, a novel improved fractional order variable step size (FOVSS) incremental conductance (Inc-Cond) tracking algorithm is designed and verified with MATLAB simulation and experimental environment. The major difference between the suggested technique and existing tracking technique includes elimination of the additional PI control loop and investigates the effect of novel Improved FOVSS IncCond control technique. This paper includes huge contributions such as how improved VSS Inc-Cond is derived based on fractional order derivative method, how DC to DC soft switching Luo converter is designed, and how comparison between the proposed scheme and existing system is done with the help of simulation and experimental arrangement. The experimental and simulation results demonstrate that the suggested controller tracks the peak power of the photovoltaic scheme in variable insulation with quick transient response. Since current and voltage of the solar photovoltaic are utilized as input elements, it has controller characteristics with variable step size. Thus, fluctuations around peak power are significantly eliminated. Thus the suggested FOVSS IncCond based peak tracking algorithm increase the power output 4.75 times the conventional power output for low load conditions. Accordingly, it is seen that the suggested technique is favorable for quick varying climatic situation. 


\section{Nomenclature}

$\begin{array}{ll}\text { T: } & \text { Temperature } \\ \text { G: } & \text { Irradiance } \\ \text { MPPT: } & \text { Maximum power point tracking } \\ \text { MPP: } & \text { Maximum power point } \\ \text { PV: } & \text { Photovoltaic } \\ \text { Inc-Cond: } & \text { Incremental conductance } \\ \text { ADC: } & \text { Analog to digital converter } \\ \text { FSS: } & \text { Fixed step size } \\ \text { FOVSS: } & \text { Fractional order variable step size } \\ D: & \text { Duty cycle } \\ A: & \text { Appendix } \\ \text { SW: } & \text { Switch } \\ \text { VSS: } & \text { Variable step size } \\ \text { I: } & \text { Current } \\ V: & \text { Voltage } \\ \text { MP: } & \text { Maximum power } \\ \text { FO: } & \text { Fractional order } \\ \text { FOD: } & \text { Fractional order derivative } \\ \text { ZVS: } & \text { Zero voltage switching } \\ \text { ZCS: } & \text { Zero current switching. }\end{array}$

\section{Conflict of Interests}

The authors declare that there is no conflict of interests regarding the publication of this paper.

\section{References}

[1] C.-H. Lin, C.-H. Huang, Y.-C. Du, and J.-L. Chen, "Maximum photovoltaic power tracking for the PV array using the fractional-order incremental conductance method," Applied Energy, vol. 88, no. 12, pp. 4840-4847, 2011.

[2] A. Al Nabulsi and R. Dhaouadi, "Efficiency optimization of a DSP-based standalone PV system using fuzzy logic and DualMPPT control," IEEE Transactions on Industrial Informatics, vol. 8, no. 3, pp. 573-584, 2012.

[3] S. Subiyanto, A. Mohamed, and M. A. Hannan, "Intelligent maximum power point tracking for PV system using Hopfield neural network optimized fuzzy logic controller," Energy and Buildings, vol. 51, pp. 29-38, 2012.

[4] N. Patcharaprakiti, S. Premrudeepreechacharn, and Y. Sriuthaisiriwong, "Maximum power point tracking using adaptive fuzzy logic control for grid-connected photovoltaic system," Renewable Energy, vol. 30, no. 11, pp. 1771-1788, 2005.

[5] T. Tafticht, K. Agbossou, M. L. Doumbia, and A. Chériti, "An improved maximum power point tracking method for photovoltaic systems," Renewable Energy, vol. 33, no. 7, pp. 15081516, 2008.

[6] A. A. Ghassami, S. M. Sadeghzadeh, and A. Soleimani, "A high performance maximum power point tracker for PV systems," Electrical Power and Energy Systems, vol. 53, pp. 237-243.

[7] T. K. Soon, S. Mekhilef, and A. Safari, "Simple and low cost incremental conductance maximum power point tracking using buck-boost converter," Journal of Renewable and Sustainable Energy, vol. 5, pp. 023106-023110, 2013.

[8] L. Guo, J. Y. Hung, and R. M. Nelms, "Comparative evaluation of sliding mode fuzzy controller and PID controller for a boost converter," Electric Power Systems Research, vol. 81, no. 1, pp. 99106, 2011.
[9] D. Rekioua, A. Y. Achour, and T. Rekioua, "Tracking power photovoltaic system with sliding mode control strategy, Energy Procedia, vol. 36, pp. 219-230, 2013.

[10] K. Punithaa, D. Devaraj, and S. Sakthivel, "Development and analysis of adaptive fuzzy controllers for photovoltaic system under varying atmospheric and partial shading condition," Applied Soft Computing, vol. 13, pp. 4320-4332, 2013.

[11] A. I. Dounis, P. Kofinas, C. Alafodimos, and D. Tseles, "Adaptive fuzzy gain scheduling PID controller for maximum power point tracking of photovoltaic system," Renewable Energy, vol. 60, pp. 202-214, 2013.

[12] S. Lalouni and D. Rekioua, "Optimal control of a grid connected photovoltaic system with constant switching frequency," Energy Procedia, vol. 36, pp. 189-199, 2013.

[13] A. Safari and S. Mekhilef, "Simulation and hardware implementation of incremental conductance MPPT with direct control method using cuk converter," IEEE Transactions on Industrial Electronics, vol. 58, no. 4, pp. 1154-1161, 2011.

[14] F. Liu, S. Duan, F. Liu, B. Liu, and Y. Kang, "A variable step size INC MPPT method for PV systems," IEEE Transactions on Industrial Electronics, vol. 55, no. 7, pp. 2622-2628, 2008.

[15] Q. Mei, M. Shan, L. Liu, and J. M. Guerrero, "A novel improved variable step-size incremental-resistance MPPT method for PV systems," IEEE Transactions on Industrial Electronics, vol. 58, no. 6, pp. 2427-2434, 2011.

[16] D. A. R. Wati, W. B. Pramono, and R. D. G. Wibowo, "Design and implementation of fuzzy logic controller based on incremental conductance algorithms for photovoltaic power optimization," in Proceeding of the International Conference on Sustainable Energy Engineering and Application (ICSEEA'12), pp. 6-8, Yogyakarta, Indonesia, November 2012.

[17] M. H. Taghvaee, M. A. M. Radzi, S. M. Moosavain, H. Hizam, and M. H. Marhaban, "A current and future study on non-isolated DC-DC converters for photovoltaic applications," Renewable and Sustainable Energy Reviews, vol. 17, pp. 216-227, 2013.

[18] M. A. Al-Saffar, E. H. Ismail, and A. J. Sabzali, "Family of ZCZVS converters with wide voltage range for renewable energy systems," Renewable Energy, vol. 56, pp. 32-43, 2013.

[19] T. Esram and P. L. Chapman, "Comparison of photovoltaic array maximum power point tracking techniques," IEEE Transactions on Energy Conversion, vol. 22, no. 2, pp. 439-449, 2007.

[20] K. Ishaque, Z. Salam, M. Amjad, and S. Mekhilef, "An improved particle swarm optimization (PSO)-based MPPT for PV with reduced steady-state oscillation," IEEE Transactions on Power Electronics, vol. 27, no. 8, pp. 3627-3638, 2012.

[21] D. P. Hohm and M. E. Ropp, "Comparative study of maximum power point tracking algorithms," Progress in Photovoltaics: Research and Applications, vol. 11, no. 1, pp. 47-62, 2003.

[22] R. Arulmurugan and N. V. Suthanthira, "Intelligent fuzzy MPPT controller using analysis of DC to DC novel Buck converter for photovoltaic energy system applications," in Proceedings of the International Conference on Pattern Recognition, Informatics and Mobile Engineering, pp. 225-231, February 2013.

[23] R. Rahmani, R. Yusof, and M. Seyedmahmoudian, "Hybrid technique of ant colony and particle swarm optimization for short term wind energy forecasting," Journal of Wind Engineering and Industrial Aerodynamics, vol. 123, part A, pp. 163-170, 2013. 

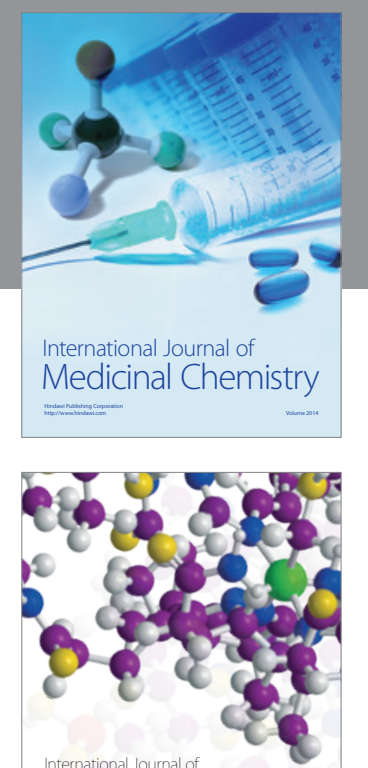

\section{Carbohydrate} Chemistry

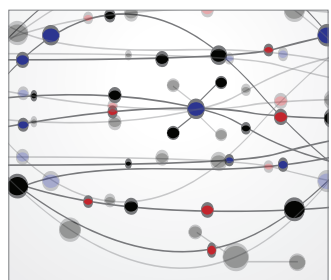

The Scientific World Journal
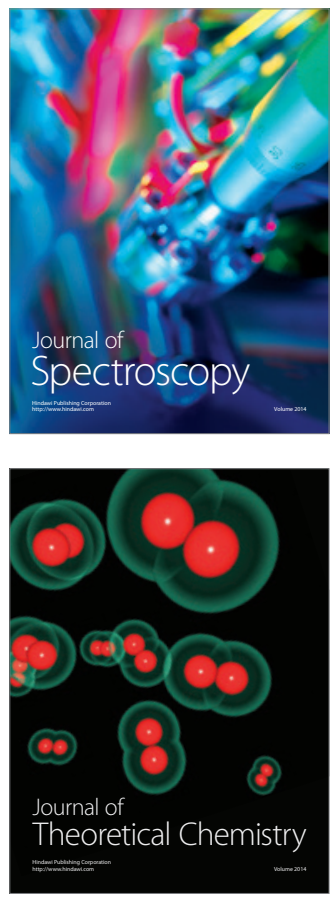
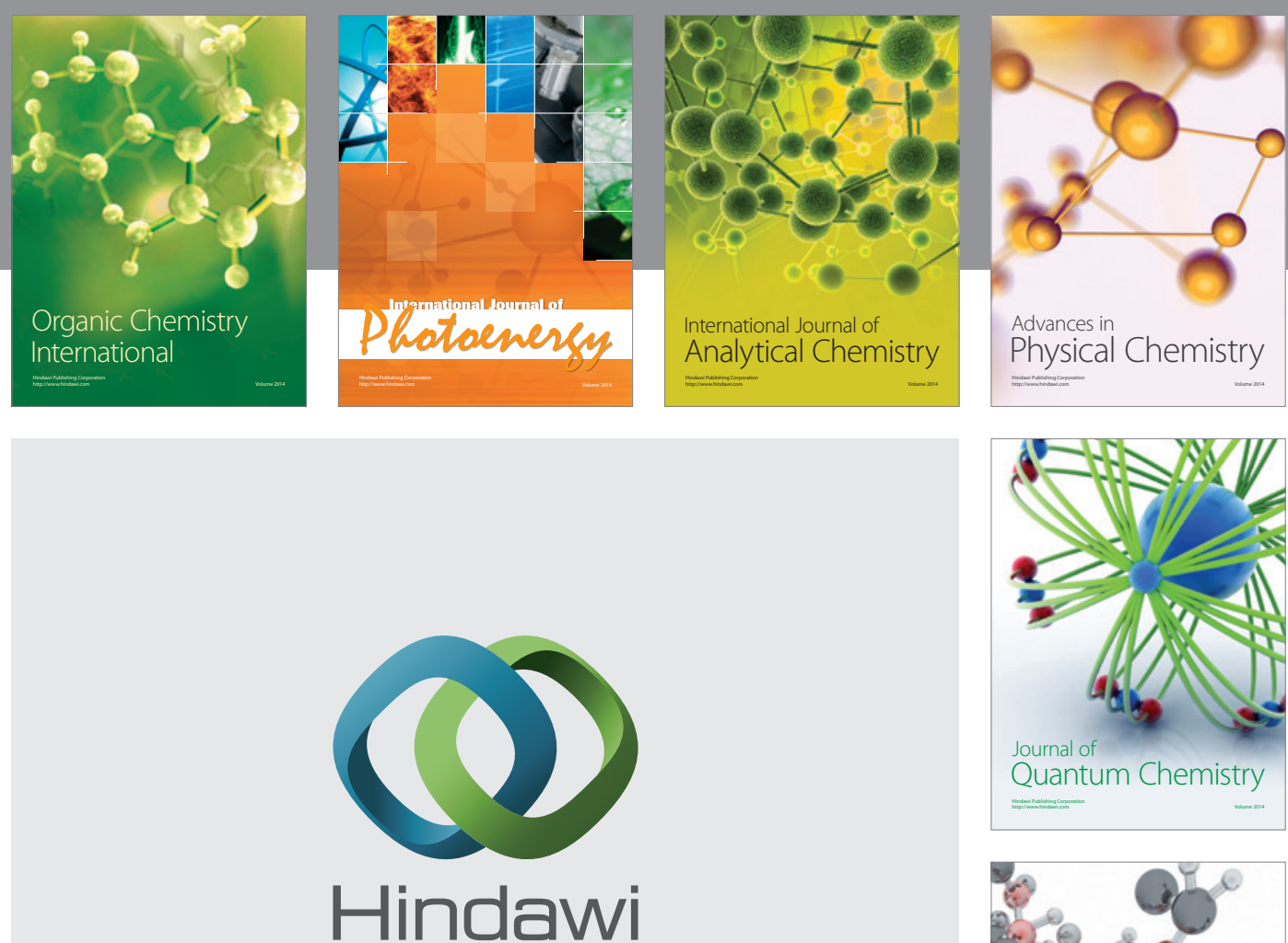

Submit your manuscripts at

http://www.hindawi.com

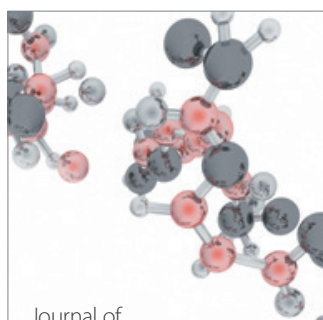

Analytical Methods

in Chemistry

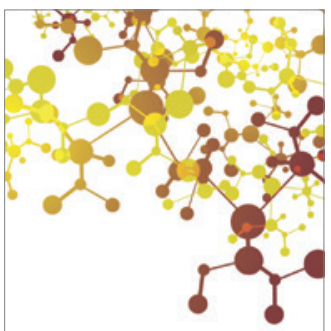

Journal of

Applied Chemistry

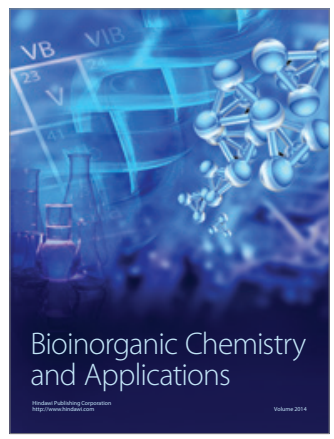

Inorganic Chemistry
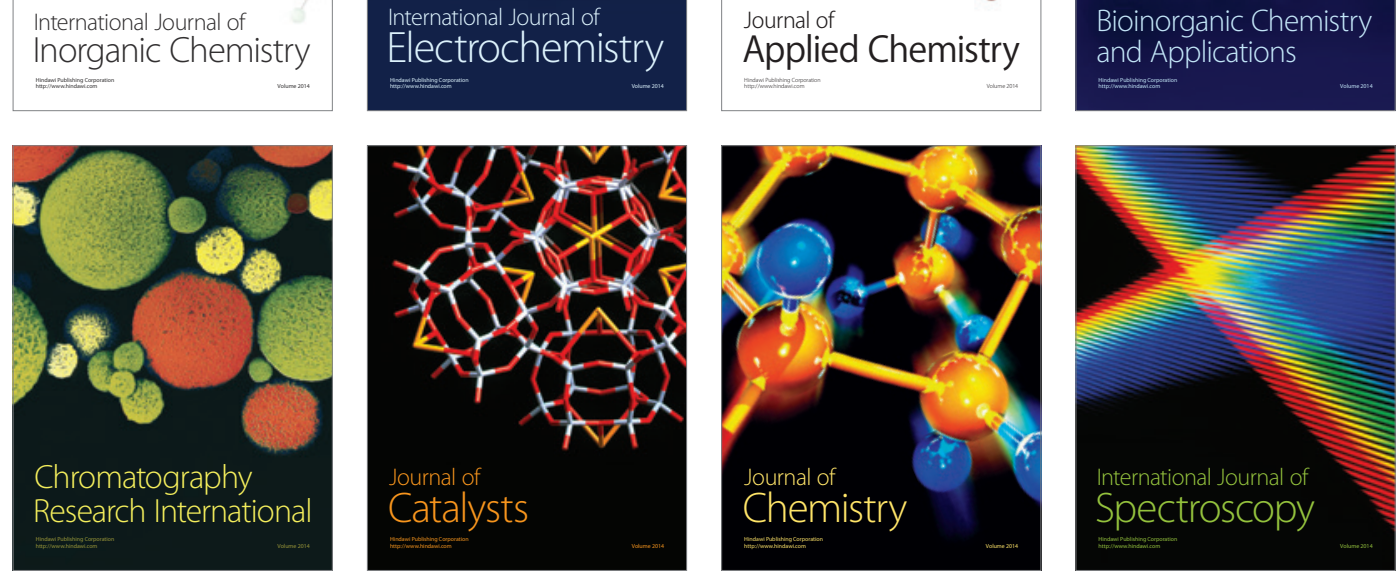